\title{
Building Relationships in a Cold Climate: A Case Study of Family Engagement within an 'Edge of Care' Family Support Service
}

\author{
Robin Sen \\ Department of Sociological Studies, University of Sheffield \\ E-mail:r.n.sen@sheffield.ac.uk
}

Drawing on a case study generated as part of a larger evaluation, this article explores engagement between one family and an 'edge of care' intensive family support service, within a cold climate of public spending cuts and rising numbers of children in care. The focus on engagement in the case study illustrates theories about relationship building at the 'edge of care': the importance of an empathic relationship; harnessing parents' agency for change while raising child welfare concerns; allowing parents space to maintain a positive self-conception of parenthood while supporting improvements; and engagement with family practices. The case study highlights that, despite the potential disciplinary aspects of intensive family support, the parents valued the 'edge of care' service because it provided them with the help they felt they needed, contrasting with their prior experience of statutory child welfare agency practice.

Key words: Family support, child protection, child neglect, child welfare, intensive support.

\section{Introduction}

Family preservation services focussed on maintaining children within birth family settings have developed since the 1950s in Anglophone countries. In the UK, they were given further impetus by the Labour government's Green Paper, Care Matters (DfES, 2006), which introduced the phrase 'edge of care'. The paper articulated the aim of 'avoiding the need for care, except for those who truly need its support' (ibid.: 21). 'Edge of care' services fall into a strand of intensive family support focussed on multi-agency responses where there are multiple, entrenched and complex difficulties (DfES, 2006; Thoburn et al., 2011), and are based on the Family Intervention Project (FIP) model developed under the Labour government. This consisted of: a focus on the most 'problematic' families; a 'whole family' approach; a dedicated key worker working intensively with the family according to a structured model of contact; the use of a contract of expectations with families, entailing sanctions for non-compliance; and the use of 'evidence-based' parenting programmes (White et al., 2008: 12-13).

Government funded evaluations of FIPs found that these projects led to reductions in anti-social behaviour and offending, improvements in school attendance and family functioning and that families generally welcomed the support provided (see White et al., 2008; Flint et al., 2011). Although differences in role must be borne in mind, this contrasts with evidence from studies of more routine social work family support practice 
in the UK and other Anglophone countries, highlighting that relationships between child protection social workers and parents often become strained (for example, Dumbrill, 2006). UK studies of 'edge of care' projects have also found parents' positivity about these services contrasts with more ambivalent views of statutory child and family social work provision (Forrester et al., 2008; Mason, 2012) The rigour of the evidence base for FIPs is, however, contested (Gregg, 2010), and there have also been critical questions about both the disciplinary technologies of control associated with aspects of FIPs' operation and their capacity to address longer-term and underlying difficulties faced by families with complex needs (Flint et al., 2011). The social construction of 'problem families' within the development of the FIP agenda has generated particularly fierce criticism (see Garrett, 2007). It is evident that the subjection of particular families to the scrutiny of intensive family support is morally and politically charged: often classified as troublesome, in many cases these are also families affected by issues of health, disability and social disadvantage (Gregg, 2010; Flint et al., 2011). However, while acknowledging FIPs reflect governmental intention to control the conduct of vulnerable families, Parr (2011) and Flint (2012) draw on evidence of parental experience at the local level which suggests they can, nonetheless, offer families valued welfare-orientated support.

In 2011, the Coalition government introduced the Troubled Families Programme (TFP), identifying nearly 120,000 families for intervention who '[c] ause high costs to the public purse', totalling an estimated £9bn (DCLG, 2012a: 3). The Programme represented an additional $£ 448 \mathrm{~m}$ investment (Churchill, 2013) in intensive family support in order to '[turn] around the lives of troubled families', with the expectation that most families would exhibit specified changes within a year of intervention (DCLG, 2012a: 11). Reducing future state expenditure was an explicit aim of the Programme, with local authorities subject to 'Payment by Results' whereby, to receive maximum government funding, they had to evidence change for families in defined areas linked to government spending on those families (DCLG, 2012a). The TFP built on the FIP programme rather than replacing it; in some areas 'Troubled Family' teams co-exist alongside FIP teams, while in others, FIP services have been subsumed under the auspices of the TFP. The influence of the FIP model on the TFP is reflected in the focus on the key worker role and the implied 'challenge and support' philosophy (DCLG, 2012b). Like the FIP agenda, the TFP emphasised individual and family level, rather than structural, explanations of families' difficulties, locating them within the inter-generational transmission of abuse and family dysfunction, individual family characteristics and anti-social family networks (see Casey, 2012). However, whereas FIPs developed alongside increased welfare spending, large public spending cuts have accompanied the TFP, reducing wider welfare support to those same families whom the TFP has targeted. Reed and Elson (2014) found that the 2010-15 tax and benefits changes produced a 10 per cent fall in average income for the poorest decile of households, the largest fall of any decile, while drastic reductions in local authority funding have seen cuts to children's centres, youth work and family support services (Churchill, 2013) which poorer families use disproportionately.

In addition to the challenges posed by welfare and service cuts, 'edge of care' services appear precariously positioned within the child protection policy context emerging since the Coalition. From 2007/08, the number of children in care in England and Wales has actually risen each year. The rise began before the Coalition government assumed office, and was initially connected to the public and media response, in 2008, to the death of Peter Connelly. However, the Coalition did strongly promote increased use of adoption 
as a response where birth families with multiple and complex difficulties were struggling to maintain care of young children (Featherstone et al., 2014). While the promotion of adoption is not tied to a view that more children should come into the care system, neither the Coalition nor the current Conservative administration have expressed concern about rising care numbers, and one influential advisor to the current and last governments linked the increased use of adoption to the earlier removal of children from birth families in cases of neglect (Narey, 2011). Towards the end of its period of office, however, the Coalition did commission new 'edge of care' services for teenagers where behavioural issues were a primary concern (DfE, 2014). These divergent policy responses - the TFP, public spending cuts and welfare residualisation, the promotion of adoption for young children alongside family preservation and behavioural change for teenagers - are logically connected by a goal of minimising future state expenditure on, and liability for, vulnerable children and families. As this policy context develops under the current Conservative government, it is unclear what space there will be for 'edge of care' services, like the one described in this article, which seek to work with children of all ages, in families where difficulties are unlikely to be amenable to quick resolution.

This article utilises a case study from a larger evaluation of a Family Support Service (FSS), an 'edge of care' intensive family support service, to explore how relationships were built and sustained between the service and the Hughes ${ }^{1}$ family. It firstly describes the FSS service and wider evaluation study before outlining the issues behind the Hughes family's referral to the FSS, the work undertaken between the family and service and the summary outcomes of this work. It goes on to analyse key factors underpinning the positive engagement between the FSS and the family, concluding by evaluating the strengths and gaps within the approach offered by the service within the current policy context.

\section{The FSS service and evaluation}

The FSS researched for this study was an English local authority funded service, managed within Children's Services, but located separately to social work teams. While located alongside a TFP team, the FSS service was separately funded by the local authority, only taking referrals from social workers where families had children who were at risk of coming into care. Key features of the service included:

- Intensive support for up to two years adopting the FIP structured approach (see Figure 1). The referring social worker remained allocated to the family during the FSS's involvement.

- An office hours service only, available Monday to Friday.

- The provision of specific parenting and support courses (for example, cooking) linked to family functioning.

- A model in which behaviour change theory, social learning theory, strength-based family support practice and relationship-based practice were all evident. As such, the FSS used behavioural incentives (shopping vouchers and family days out) and sanctions (warning letters regarding missed appointments and, ultimately, the withdrawal of the service) alongside the modelling of parenting practices and a key working approach which emphasised fostering nurturing relationships with families. 
FSS manager and allocated social worker visit parents jointly. If parents accept service, key worker allocated to family. Key worker must have at least three weekly contacts with family via mixture of phone contact, home visiting, office-based contact and community activities.

\section{$\downarrow$}

FSS multi-agency referral meeting with parents and relevant agencies within two weeks, chaired by the key worker. Thereafter, FSS multi-agency review meetings chaired by the key worker or FSS manager every six to eight weeks.

Whole family assessment completed by key worker within six weeks of allocation.

Based on assessment, commitment contract outlining roles and responsibilities is signed by parents and each key agency. Support plan for the family is also drawn up detailing more specific support and actions.

\section{$\downarrow$}

Exit meeting to confirm end of FSS involvement and agree a plan of ongoing support for family from other agencies.

Figure 1. FSS structured intervention based on FIP approach, key stages

The evaluation of the FSS used a qualitative case study design (Yin, 2009) to explore agency practice and changes in nine families who were purposively selected to give some variation in length of involvement with the FSS, allocated key worker and family composition. The study utilised multi-modal data to build insights on each case, moving recursively between the different data sources and themes within pre-existing literature to produce an account of practice. As case study designs build inductively from multiple sources they tend to have strong internal validity but weak external validity, given that findings cannot be readily applied beyond the selected case(s) (Eisenhardt and Graebner, 2007). Cross-case comparison was undertaken within the wider study to build a theory of change across the nine families (Churchill and Sen, 2015), but only themes arising from the Hughes family are presented here. This case was chosen as one where the family had completed their full involvement with the FSS in the course of the study, and during which both the parents and child welfare agencies felt they had made marked progress. A prominent theme arising from the data was the parents' strongly contrasting experiences of the FSS and 'ordinary' child welfare services. The discussion 
therefore provides critical analysis of the difference in service responses, focusing on what kinds of practice supported the parents to move their lives on. It draws on the following sources: joint parental interviews in May and July 2013; separate interviews with the eldest daughter, Susan, on the same dates; an interview with the key worker, Lesley, in May 2013; an observation of Lesley working with the family in June 2013; informal observation of the FSS team in their offices; a telephone interview with the case holding social worker in July 2013; and analysis of the FSS case file data on the family.

\section{The Hughes family: referring issues, summary of work and outcomes}

The Hughes are a white English working-class family who worked with the FSS from August 2011 to June 2013. In August 2011, the family comprised Sally (37), Richard (40), and their children Luke (15), Susan (14), Steve (8) and Will (4). At referral, case records indicated the Hughes were experiencing long-term and complex difficulties affecting family functioning and parenting. There had been on/off child and family social work involvement since 2007, and consistently since 2009. Agencies' concerns focussed on a lack of hygiene, safety and furnishing within the family home, and the quality of parenting. All four children were placed on the Child Protection Register, category of neglect, in 2010.

Since that time, there had been missed appointments with child welfare agencies and all the children had missed health appointments. The parents were unemployed, in significant debt and there were agency concerns about how the limited household income was being spent, with sparse household furnishing and children's play items. Agencies observed a lack of parental boundaries and guidance for the children, and Will's lack of speech development (he was only speaking a few words at four years of age) was compounded by missed speech therapy appointments. Sally's mental well-being was also noted as a concern. She had experienced post-natal depression after Will's birth, but no subsequent mental health diagnosis was recorded. However, agencies were concerned about her emotional presentation and mood swings.

These difficulties were compounded when the family became homeless following eviction from their local authority tenancy, due to close to $£ 1,500$ rent arrears, in mid2011. The family had lost their previous tenancy for the same reason, and were deemed ineligible for another local authority tenancy due to accumulated rent arrears and damage sustained to a previous tenancy. In August 2011, the family had just found a privately rented house with social work support. Case records show the local authority had closely considered initiating care proceedings to remove the children due to 'chronic neglect'. Instead, it decided to proceed with a referral to the FSS.

This summary of issues is largely based on case records which reflect professional framings of family difficulties and fit them into, sometimes rigid, descriptive categories (White et al., 2009). Nonetheless, the information suggests why the family had come under the "disciplinary" gaze of a range of agencies' (Parr, 2011: 731). Several of the noted concerns - parental mental health difficulties, poor parenting and poverty - are associated with child neglect, the long-term effects of which can impact on all aspects of child development (Daniel et al., 2011). The nature of the concerns also suggested care proceedings were likely. Brophy and colleagues' (2006) research review of care proceedings in England found that 40 per cent involved families with parental mental ill 
health, 50 per cent families with housing problems and over 70 per cent families where parents were seen to be uncooperative with supports for their children.

Following the six-week assessment period, the FSS work focussed on:

- Budgeting work with the parents alongside welfare benefit maximisation.

- Practical support to facilitate improvements to the home environment.

- Emotional and psychological support through listening to the parents' concerns and encouraging better family communication via weekly family activities.

- Problem solving support around emerging family issues.

- Tailored parenting support delivered by the FSS parenting support worker.

- Monitoring the children's attendance at school and medical appointments, the parents' attendance at agency meetings, the family home environment and rent payments.

- Liaising between other involved agencies and the parents regarding concerns and progress.

By June 2013, the children all remained within the family, their names had been removed from the Child Protection Register, and the social work team were planning to end their own involvement later in the year. Underlying these changes were a number of overall improvements. Both parents were noted to be parenting more confidently and effectively, with better communication within the family. Sally's emotional presentation was better, although she had declined to access mental health services, despite encouragement from the FSS. Sally and Richard remained unemployed, but their benefits had been maximised and they were largely debt free, with their tenancy maintained without rent arrears. The home environment, though inconsistent, was much improved. Luke had completed school but subsequently dropped out of a college course. He was not in employment or education by June 2013. School feedback on the other three children was positive: Susan had a place at college to study design from the next academic year; Steve had received glowing reports and recognition as one of the children in his class with perfect attendance for the last term; Will had successfully started primary school and made good progress in respect of his speech development.

\section{Engagement between the Hughes family and the FSS}

Two of the referral criteria for the FSS were that a family had the capacity to change and they consented to the work with the service. Sally described the parents' early fears that the FSS was in fact 'more for them to take us to court to get the kids off us'. Poor relationships with the social work team at that time reinforced this view. They stated they knew little about the FSS and agreed to work with them because they felt they had to:

Like [the FSS] were the last chance, either way, do you know what I mean? We had to take it even though we did have fears. (Richard)

The disciplinary techniques of FIPs carry sanctions for non-engagement, which can sometimes include housing eviction and legal penalties through the criminal justice system (Parr, 2011). In contrast, the FSS's focus on voluntary engagement gave parents control over whether they accepted the service. However, refusal of the service, or its later withdrawal through non-engagement, would likely lead the local authority to initiate care proceedings and, indeed, a family's very refusal to engage with the FSS would likely form 
part of the grounds for doing so. Garrett (2007: 221) has argued that some families offered support through FIPs were 'coerced and hoodwinked at the point of referral'. This would be an inaccurate characterisation of the FSS's practice. It is, however, clear why Sally and Richard might view accepting the offer of the FSS as a 'catch-22' situation, despite the emphasis on voluntarism.

Richard stated their fears about the FSS 'all subsided very quickly'. He felt the family problems were '[t]hings that could be sorted with the right help very easily', and it was a matter of being persuaded that the FSS would offer that. The parents' narrative suggested features identified as important in other 'edge of care' projects were significant in convincing them. These included harnessing the parents' agency for change (Forrester et al., 2008) and establishing shared goals, with clear communication about what needed to change, while still respecting the parents' perspectives on their circumstances (Thoburn et al., 2011; Mason, 2012):

Richard: Since Lesley and the team have come on board ... we don't feel as though we're being made to do some stuff to keep us children. They set a criteria for us to adhere to, yeah. And left us to do it.

Sally: They've [the FSS] always not beat about the bush just told us straight which I accept and I'm grateful for them doing that ... we've got a mutual understanding of things and that. And where I need to better myself as a parent, as well for my kids.

Richard summarised the FSS's approach with the comment that '[t]hey've just been generally caring'. Formal and informal observation of the FSS revealed some similar characteristics in ethos to the Westminster Family Recovery Project (Thoburn et al., 2011), in terms of a nurturing culture towards families running throughout the team. Small caseloads, family activities based at the FSS offices, the accessible and open-plan lay out of the FSS offices and the fact that some services (such as parenting programmes) were jointly delivered by FSS staff meant the FSS manager, key workers and the team administrator all personally knew the whole Hughes family.

The affective dimensions underpinning relationship-based practice were implicit in Lesley's arrival at a 'mutual understanding' with Sally and Richard, particularly the connections between internal and external worlds and past history and current functioning (Ruch et al., 2010). Notably, both the FSS support plan and the parents' self-definition of family difficulties accepted the core concerns identified in the referral summary above. For the parents, this included accepting the label of 'neglect' (see Table 1).

However, discussion with Lesley helped them view this categorisation in a way which did not exclude a positive self-concept of parenthood:

Richard: This is another thing, Lesley says there are different areas of neglect.

Interviewer: Yeah.

R: We weren't neglectful loving of us kids.

I: Yeah.

R: As in looking after us kids properly

I: Uh huh. Yeah.

R: If you know what I mean. 
Table 1 From parental interviews, sally and richard's self-defined family difficulties and self-assessed change

\begin{tabular}{ll}
\hline \hline & Rating of change start to end FSS involvement \\
Key family difficulties & 10 'most concerned' $\rightarrow 1$ 'least concerned' \\
\hline Neglect & $5 \rightarrow 2$ \\
Home conditions & 7 or $8 \rightarrow 2$ \\
Confidence in self as parents & $7 \rightarrow 1$ \\
Relationship Sally and Richard & 4 or $5 \rightarrow 1$ \\
\hline \hline
\end{tabular}

\section{I: Yeah. \\ R: We didn't neglect us kids' feelings or emotions.}

Sykes' study (2011) of US mothers subject to child protection referrals involving neglect illustrated how some mothers would fiercely resist the spoiled identity associated with being labelled as a neglectful parent, even though this very resistance could make them appear unwilling to acknowledge professional concerns. Sally's description of her mindset before the FSS referral suggested how debilitating the prospect of having to accept the spoiled identity of 'failed parenthood' was:

We weren't getting nowhere, to the point where I felt like, as much as I love, live for my kids. I love my kids. That was the day I had to quit, to do anything. I just failed at everything, even though I tried not to.

This was evocative of Davies' description (2011: 208) of the 'crushing force of being suspected of being a bad mother'. Sally had experienced the care system herself as a teenager. Weston (2013) found care leavers who had become parents feared their own history of being parented might repeat, leading to discrepant feelings about the external world, wanting the support and connection it offered, while fearing it as a potential source of negative judgement of them as parents. A similar ambivalence was evident in Sally's description of her feelings before the FSS's involvement:

Sally: I was trying to keep the house clean. They were giving me lots of tasks to do, what I tried to, as well as going through a rough bit with my husband as well at the time. I tried holding it altogether, I was too proud to ask for help. And that's where I went wrong.

Richard: And I did ask for help.

Sally: Because I thought women, being a mother, I wouldn't be a good mother, if I couldn't do that for my kids.

Sally graphically described her outlook at the start of the FSS involvement as being 'like a maze I were in and it was just dark, it was pitch black'. In May 2013, by contrast, she felt that '[t]he maze has lit up, it's not a maze now. It's like, my dream, my wish has come true.' That Lesley's approach provided space for the parents to maintain a positive 
self-concept as parents while improvements to their parenting were supported seemed crucial in underpinning this change. Some twenty months after the start of the FSS's involvement, Lesley and Sally independently recalled Lesley noticing emotional warmth within the family during her first visit. Lesley's recollection of this visit suggested how, from this first meeting, she had tried to engage with the lived experience within the household:

Lesley: So I went and yeah this family was there, and the self-esteem was really low, and their confidence was really low. But then I saw things within the family, Robin, because the family were all sat together. And they were sharing, I think somebody opened some popcorn or something. And they all shared it.

This recognition can be linked to a strengths-based approach (Thoburn et al., 2011) and empathic relational practice (Ruch et al., 2010). It also resonates with Morris' (2013) emphasis on the importance of professionals engaging with everyday 'family practices' within vulnerable families. Susan's comments on Lesley's overall work identified Lesley 'being with' the family as a valued characteristic of her approach:

Interviewer: What do you think has been the most helpful thing that Lesley's done?

Susan: Not just the support but the fact that she's actually, you know, been here and she's helped us through a lot and the fact that she like, took us out for a family day and brought us all together. I mean, like, we work together to achieve something and I think that helped.

Lesley was observed 'being with' the family during a regular, monthly, games activity which formed part of the FSS support plan, in order to improve family communication and togetherness. Here, symbolically and literally, Lesley was part insider and part outsider. Lesley's outsider status was underlined by her bringing board games from the FSS office to the family home for the activity. Yet she was readily accepted into the family's domesticity, at evening time, for what would, ordinarily, be an activity reserved to those part of an intimate family and friends network. Her role, however, was not as participant, but facilitator of the family members playing together, sitting slightly outside the family circle when the games were played, offering help when required. Flint (2012: 834) has characterised key workers within intensive family support as having 'an ambiguous and "liminal" status: neither entirely formal professional clinicians, nor purely informal social carers'. Lesley's 'liminal status' was suggested by Richard's characterisation of her relation to the family:

If we have any problem with kids or anything like that, I would just mention to Lesley and she would come back with advice ... She has a way of going about it. I wouldn't say she's a friend. But it feels like she's a part of the circle sort of thing.

Lesley's acceptance as 'part of the circle' allowed her privileged access to the family's experiences. This could have proved problematic, given that key worker inspection of domesticity incorporates a disciplinary dimension, providing scrutiny of, ordinarily private, family practices (Flint, 2012). Sally and Richard were, though, aware of, and appeared to accept, the disciplinary aspects of Lesley's role: 
Richard: If Lesley's got something to say, she'll say it. Either way, against us or for us, she'll say it. And has done.

The parents revealed they had been given a warning letter from the FSS manager regarding missed appointments, approximately a year into their involvement, which they felt had been justified. Case file data provided other examples. In April 2012, Lesley had warned the parents that their engagement needed to improve after they had missed an important appointment for the children and she had subsequently found the two younger children unwashed and undressed at lunch time during a subsequent visit. In August 2012, Lesley had visited and noticed Will had a bruise around his eye. The parents stated he had fallen against furniture a few days earlier and they had tended to the injury themselves. She questioned why they had not taken Will for medical attention, and referred the matter to the social worker, who visited, and decided no further action was needed.

It is likely that the goodwill Lesley had built up allowed her scope to exercise the disciplinary aspects of her role without resentment. It was also evident that she continued to engage with the family's lived experiences and respect the parents' perspectives when things became more difficult. For instance, in the summer of 2012, one of a number of problems facing the family was that Richard felt unwell and had lost weight, but refused to see a doctor. Lesley exhibited concern for his individual welfare by persuading him to go to his GP and accompanying him to the appointment. But, at Richard's request, she did not go into the consultation with him. It transpired Richard had a stomach ulcer, which was manageable through medication, and his health subsequently improved.

Sally and Richard's narrative suggested that they actually welcomed the intensity of Lesley's visits. This needs to be understood within the context of their previous experience. Dumbrill (2006) differentiated between parents' experience of child welfare professionals exercising 'power over' them and those exercising 'power with' them. Previous child welfare visits were of the first category, where the parents felt subject to a periodic, critical, 'disciplinary gaze' (Parr, 2011). Sally and Richard recalled a Health Visitor who, rather than recognising that they had managed to salvage a carpet for their home, criticised that it was stained. A duty social worker's visit was also poignantly remembered:

Richard: We'd just moved in, there were no carpets on the floor, there were no settee. And within a couple of weeks, I've got a carpet down and things.

Sally: That table.

R: New table, new settee. I've got carpet in here.

S: And he [the social worker] just says, 'Things haven't changed, have they?'.

R: ... He didn't walk in and notice that we'd actually done anything.

The parents believed that child welfare agencies were convinced they were not acting in the best interests of their children and were only seeking to confirm this view rather than support them. In turn, their mistrust of agencies played some role in their seeming lack of co-operation:

Richard: All they were doing were finding things to take the children off us. That's all ... I just packed in going to the meetings because if I said something, I were being aggressive. But, if I didn't go, I were being uncooperative. 
Lesley's role was, by contrast, experienced as exercising 'power with' (Dumbrill, 2006). Improvements in the family situation which were identified were accompanied with practical or emotional support to address them. For example, she supported the family to acquire items of new furniture to improve the home environment. Sally and Richard welcomed the frequency of Lesley's visiting because they felt she gained a fairer assessment of their family practices through this than statutory agencies had in more periodic inspections of the family home:

Richard: She stood up for us in the meetings. It's the first time anyone had. Because she was coming all the time and she actually saw what it were.

Richard's statement suggested that he might see Lesley in an advocacy role in opposition to statutory child welfare agencies. This could have reinforced the parents' negative perception of these organisations. In fact, there was evidence that the FSS's involvement helped rebuild trust between the parents and other professionals. The current family social worker acknowledged that 'Lesley built up a very strong relationship with the family', but expressed no concerns that it had been collusive, while Richard himself commented that since the FSS's involvement 'the social worker seems to be working with us ... instead of against us'. The process of building trust was aided by changing personnel, the children moved schools in September 2011, and a new social worker was allocated to the family in 2012, but the FSS's involvement appeared to be a key catalyst. The current social worker and the parents each identified the FSS review meetings (see Figure 1) as particularly useful in establishing positive communication. Held outside of the formal child care review meetings chaired by the social work team, these task-focussed meetings allowed for supportive, but open and direct discussion, between the involved agencies and the parents, centred on the progress which had been made and what still needed to be done. This helped break down the cycle of mistrust whereby the parents felt their perspectives were not heard at multi-agency meetings, and so partially withdrew from them, which in turn engendered concern about their co-operation.

\section{Discussion and conclusion}

The core outcomes for the family are characterised in Table 2 in terms of the distinction between 'hard' and 'soft' transformative outcomes (Flint et al., $2011: 41$ ).

There was more evidence of the 'soft' outcomes relating to relational changes. 'Confidence' was a word which came up in both the family's and Lesley's narratives of change within the family. The parents also referred to the children being 'happier' compared to the start of the FSS intervention, and reported that their own relationship had improved. The evidence of 'hard' transformative outcomes was more mixed. The most obvious 'hard' outcomes were the children's diversion from care and the proposed ending of social work involvement. Prevention of entry into care does not evidence that long-term child welfare outcomes are necessarily improved though (Forrester et al., 2008), and such evidence was not collected by the study described in this article. However, the fact that four children who were at the 'edge of care' were, according to professional assessment, happily and securely sustained within their family setting, can be viewed as a significant achievement in and of itself. 
Table 2 'Soft' and 'hard' transformative outcomes in the Hughes family, derived from Flint et al. (2011)

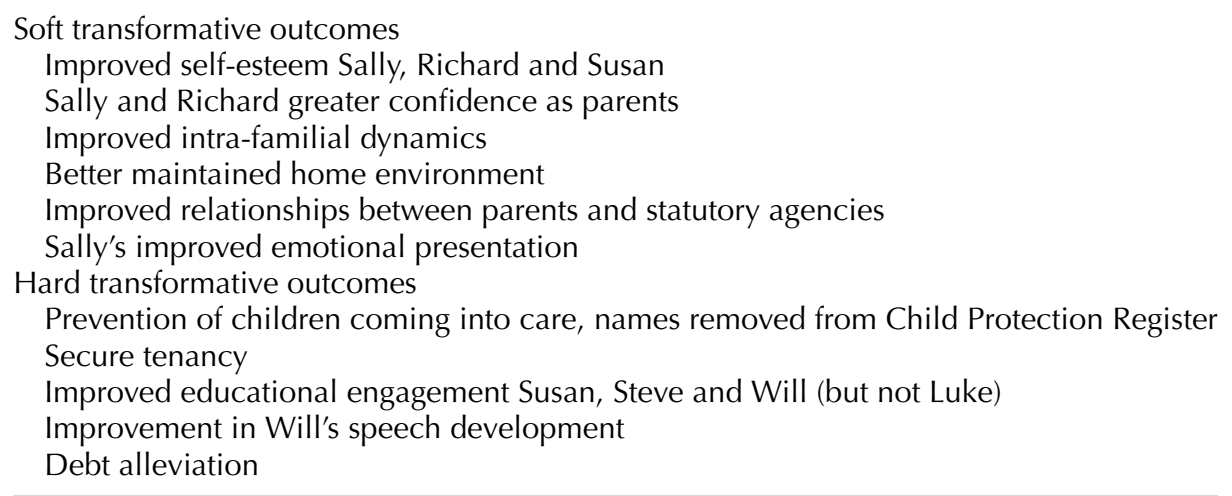

Two qualifications are worth noting. Firstly, while there was evidence of progress within the first few months of the FSS's involvement, the family's overall trajectory was non-linear, as Flint et al. (2011) found in relation to many families subject to intensive family support. Further difficulties and poorer engagement with child welfare agencies were evident around eight to twelve months after the FSS began their engagement, before subsiding. Even by June 2013 there was mixed progress in some areas, for example the educational trajectories of Susan, Steve and Will contrasted with that of Luke. Secondly, by June 2013 there was still some fragility about the family's circumstances. That Sally had not accessed mental health support services is consistent with wider evidence that the FIP model is less successful in addressing long-term mental health issues (Gregg, 2010). While Sally's confidence, outlook and coping skills had improved, the reasons for her refusal of formal mental health support were unclear. The long-term nature of many mental health issues, the fact that they can be exacerbated by poverty and family stress and the possible impact of such issues on parenting capacity (Daniel et al., 2011) marked this out as a future vulnerability. That the parents had maintained their tenancy reflected broader improvements in family functioning. However, there was still fragility in the security of their tenure, given it was a private let, and while the family's finances had stabilised, continuing welfare residualisation meant the family's income was likely to fall, with potential implications for future debt management and tenancy maintenance.

Whether, overall, this progress represented the family 'turning their lives around' depends on how the objectives of intensive family support are defined, which is a moral and political judgment, as much as the identification of which families should be subject to such intervention. The family did meet the eligibility criteria for the TFP (DCLG, 2012a: 4-5). However, had they received support under the auspices of this initiative, their progress would not have allowed the local authority to claim the full TFP 'Payment by Results' fee, as both parents remained unemployed (DCLG, 2012a). Indeed, Luke dropping out of college meant there might soon be a third unemployed adult within the household, which sits uneasily with the economic rationalities of reduced government spending underpinning the TFP. 
The final consideration, in conclusion, is whether the support provided to the family could have been provided earlier. This was the parents' only suggestion for service improvement in respect of the FSS and has a logic. However, the intensity of contact as well as the duration of involvement were key features of the FSS's engagement with the Hughes. Successful earlier provision of such support would require that parents voluntarily accept the incursion of intensive family support before extensive difficulties had become apparent, and that such support be available flexibly in response to family need. Within the context of an adoption policy prioritising the early removal of young children from families who are struggling with multiple difficulties, it may be questioned whether such earlier intervention would be acceptable to vulnerable families with younger children and, even if it were, whether it would be justifiable when other service and financial support is being removed.

\section{Acknowledgements}

I am grateful for the comments of two anonymous peer reviewers on an earlier version of this article

\section{Note}

1 All names are pseudonyms and some minor case details have been altered.

\section{References}

Brophy, J. (2006) Care Proceedings under the Children Act 1989: A Research Review, London: DCA, www.dca.gov.uk/laid/childcare.htm [accessed 15.10.2014].

Casey, L. (2012) Listening to Troubled Families, London: DCLG, www.gov.uk/government/uploads/ system/uploads/attachment_data/file/6151/2183663.pdf [accessed 03.07.2015].

Churchill, H. (2013) 'Retrenchment and restructuring: family support and children's services reform under the coalition', Journal of Children's Services, 8, 3, 209-22.

Churchill, H. and Sen, R. (2015) Evaluation of a Family Support Service, Sheffield: University of Sheffield. Daniel, B., Taylor, J. and Scott J. with Derbyshire, D. and Neilson, D. (2011) Recognising and Helping the Neglected Child: Evidence-Based Practice for Assessment and Intervention, London: Jessica Kingsley.

Davies, P. (2011) 'The impact of a child protection investigation: a personal reflective account', Child and Family Social Work, 16, 2, 201-9.

Department for Communities and Local Government (DCLG) (2012a) The Troubled Families Programme: Financial Framework for the Troubled Families Programme's Payment-By-Results Scheme for Local Authorities, London: DCLG.

Department for Communities and Local Government (DCLG) (2012b) Working with Troubled Families: A Guide to the Evidence and Good Practice, London: DCLG.

Department for Education (DfE) (2014) Rethinking Support for Adolescents in or on the Edge of Care, London: DfE, www.gov.uk/government/uploads/system/uploads/attachment_data/file/342052/ Rethinking_support_for_adolescents.pdf, [accessed 03.07.2015].

Department for Education and Skills (DfES) (2006) Care Matters: Transforming the Lives of Children and Young People in Care, London: DfES.

Dumbrill, G. C. (2006) 'Parental experience of child protection intervention: a qualitative study', Child Abuse and Neglect, 30, 1, 27-37.

Eisenhardt, K. M. and Graebner, M. E. (2007) 'Theory building from cases: opportunities and challenges', Academy of Management Journal, 50, 1, 25-32. 
Featherstone, B., White, S. and Morris, K. (2014) Re-Imagining Child Protection, Bristol: The Policy Press.

Flint, J. (2012) 'The inspection house and neglected dynamics of governance: the case of domestic visits in family intervention projects', Housing Studies, 27, 6, 822-38.

Flint, J., Batty, E., Parr, S., Platts Fowler, D., Nixon, J. and Sanderson, D. (2011) Evaluation of Intensive Intervention Projects, Research Report R113, London: DfE.

Forrester, D., Pokhrelm, S., McDonald, L., Giannou, D., Waissbein, C., Binnie, C., Jensch, G. and Copello, A. (2008) Final Report on the Evaluation of 'Option 2', Cardiff: Welsh Assembly Government.

Garrett, P. M. (2007) "Sinbin" solutions: the "pioneer" projects for "problem families" and the forgetfulness of social policy research', Critical Social Policy, 27, 2, 203-30.

Gregg, D. (2010) Family Intervention Projects: A Classic Case of Policy-Based Evidence, London: Centre for Crime and Justice Studies.

Mason, C. (2012) 'Social work and the "art of relationship": parents' perspectives on an intensive family support project', Child and Family Social Work, 17, 3, 368-77.

Morris, K. (2013) 'Troubled families: vulnerable families' experiences of multiple service use', Child and Family Social Work, 18, 2, 198-206.

Narey, M. (2011) 'The Narey Report on adoption: our blueprint for Britain's lost children', The Times, 5 July, http://www.thetimes.co.uk/tto/life/families/article3083832.ece [accessed 19.09.2013].

Parr, S. (2011) 'Family policy and the governance of anti-social behaviour in the UK: women's experiences of intensive family support', Journal of Social Policy, 40, 4, 717-37.

Reed, H. and Elson, D. (2014) An Adequate Standard of Living: A Child-Rights-Based Quantitative Analysis of Tax and Social Security Policy Changes in the Autumn Statement 2013 and the Budget 2014, London: Office of Children's Commissioner.

Ruch, G., Turney, D. and Ward, A. (eds.) (2010) Relationship-Based Social Work, London: Jessica Kingsley.

Sykes, J. (2011) 'Negotiating stigma: understanding mothers' responses to accusations of child neglect', Children and Youth Services Review, 33, 3, 448-56.

Thoburn, J., Cooper, N., Connolly, S. and Brandon, M. (2011) Process and Outcome Research on the Westminster Family Recovery Pathfinder, Norwich: UEA.

Weston, J. L. (2013) 'Care leavers' experiences of being and becoming parents', Doctor in Clinical Psychology thesis, University of Hertfordshire, Hertfordshire, http://uhra.herts.ac.uk/bitstream/handle/2299/ 13227/10280098\%20Weston\%20Jade\%20final\%20DClinPsy\%20submission.pdf?sequence = 1 [accessed 03.07.2015].

White, S., Hall, C. and Peckover, S. (2009) 'The descriptive tyranny of the common assessment framework: technologies of categorization and professional practice in child welfare', British Journal of Social Work, 39, 7, 1197-217.

White, C., Warrender, M., Reeves, A. and La Valle, I. (2008) Family Intervention Projects: An Evaluation of Their Design, Setup and Early Outcomes, London: DCSF/DCLG.

Yin, R. K. (2009) Case Study Research: Design and Methods, 4th edn, Los Angeles: Sage. 